\title{
Burden of dementia in Brazil
}

\author{
Carga de demência no Brasil \\ Ricardo NITRINI', Cleusa P. FERRI²
}

1 Universidade de São Paulo, Medical School, Department of Neurology, São Paulo SP, Brazil.

${ }^{2}$ Universidade Federal de São Paulo, Department of Psychiatry, São Paulo SP, Brazil.

Ricardo NITRINI ${ }^{1}$ (D) https://orcid. org/0000-0002-5721-1525; Cleusa P. FERRI ${ }^{2}$ iD https://orcid.org/00000002-1815-7685

Correspondence: Cleusa P. Ferri E-mail:ferricleusa@gmail.com Conflict of interest: There is no conflict of interest to declare. Authors' contributions: These authors contributed equally to this work.

Received on November 8, 2020; Received in its final form on November 8, 2020; Accepted on November 9, 2020.

\section{(c)) BY}

$\mathrm{T}$ he paper by Melo et al..$^{1}$ is an important contribution to understanding the impact of dementia in Brazil and can help define guidelines for future research and public policies in this area. The authors of this investigation should be commended for their enormous effort in gathering data from the Global Burden of Disease, the Brazilian Institute of Geography and Statistics, the Brazilian Ministry of Health, and several Brazilian epidemiological studies on dementia. By carefully analyzing these data, the authors were able to produce important findings that have significant implications for health care and policymaking in Brazil.

The increase in life expectancy over recent decades has caused a rise in the prevalence of degenerative diseases, which are more common in older adults. Dementia is one of the most common of these conditions, and despite its massive impact on the health of individuals, it has been largely neglected in Brazil and other Latin American countries, not only by policymakers but also by the general public. Estimates indicate that the prevalence of dementia will increase four-fold between 2015 and 2050 in Latin America². The population is aging rapidly in Brazil, making dementia a growing public health priority.

In a global context, the most recent figures show that Brazil has the second-highest agestandardized prevalence of Alzheimer's disease $(\mathrm{AD})$ and other dementias, after Turkey ${ }^{3}$. In 2000, AD ranked as the third and fourth most common cause of death in women and men aged 70 years or older, respectively, but by 2016, it had become the second most common cause of death for both genders. Moreover, $\mathrm{AD}$ was the third main cause of disability in men and women aged 70 years or older in 2000, but by 2016, it had become the second leading cause of disability in men in this age group, while remaining the same for women ${ }^{1}$.

One of the most important points emerging from the study is that with the rapid aging of the population, dementia will significantly rise unless measures are taken now to curb this scenario. We must remember the role that dementia prevention can have for future generations ${ }^{4}$, especially in developing countries with low levels of education and a lack of adequate control of conditions such as hypertension, obesity, and diabetes. A recent study ${ }^{5}$ suggested that $32.3 \%$ of dementia cases in Brazil could be related to seven potentially modifiable risk factors (diabetes, hypertension, obesity, sedentary lifestyle, depression, smoking, and low levels of education) and that reducing the prevalence of each of them by $20 \%$ per decade could, by 2050 , potentially reduce the prevalence of dementia in the country by $16.2 \%$.

Another point raised in the study by Melo et al. concerns the costs of dementia, which mostly fall on the family of dementia patients, particularly on young women, who have to leave their formal employment to work as untrained caregivers for a family member with dementia ${ }^{6}$.

A consideration of the limitations of the study can help guide recommendations for future studies to improve the accuracy of data across the country. The first was the paucity of epidemiological studies on dementia in Brazil, most of them concentrated in the Southeastern region of the country ${ }^{7}$. The lack of epidemiological studies on dementia from other regions makes it difficult to have an overview of the situation in regard to the disease throughout the whole country. The second issue is the lack of homogeneity of diagnostic criteria in the epidemiological studies that do exist ${ }^{7}$; this subject clearly needs to be addressed when planning future studies.

Regarding death certificates, the authors recommended using the diagnosis of the specific disease ( $\mathrm{AD}$, vascular dementia, frontotemporal dementia, Lewy body dementia, for example) and not simply dementia because these subtypes are associated with distinctive effects as to years lost due to disability (YLDs), age-standardized mortality, years of life lost (YLLs), and disability-adjusted life years (DALYs). However, we note that the use of death certificates to assess the prevalence of dementia and dementia subtypes as causes of death has proven challenging 
in Brazil in the past. In a study conducted in Catanduva, São Paulo State, $\mathrm{AD}$ was mentioned only 4 times and senile dementia only once in 40 death certificates of individuals with dementia ${ }^{8}$. This study was published 15 years ago, and whether recording specific diseases on death certificates has become more frequent in Brazil remains to be seen.

Data from the study by Melo et al. ${ }^{1}$ and other recent studies show that policymakers need to be aware of the urgency and the scale of the problem of dealing with dementia in Brazil and the need for more funding to provide the means to develop a National Dementia Plan'. Such a plan could help guide policies on the prevention and treatment of the condition and establish care strategies and research priorities for dementia in Brazil, taking into account the well-being of the 1.5 million Brazilians estimated to have dementia in this paper, as well as their family and caregivers.

\section{References}

1. Melo SC, Champs APS, Goulart RFG, Malta DC, Passos VMA. Dementias in Brazil: increasing burden in the 2000-2016 period. Estimates from the Global Burden of Disease Study 2016. Arq Neuro-Psiquiatr. 2020. https://doi.org/10.1590/0004282X20200059

2. Prince M, Guerchet M, Prina M. The epidemiology and impact of dementia - current state and future trends. Geneva: WHO; 2015. (Thematic briefs for the First WHO Ministerial Conference on Global Action Against Dementia, 16-17 March 2015). Available from: https:// www.who.int/mental_health/neurology/dementia/dementia_ thematicbrief_epidemiology.pdf?ua $=1$

3. GBD 2016 Dementia Collaborators. Global, regional, and national burden of Alzheimer's disease and other dementias, 1990-2016: a systematic analysis for the Global Burden of Disease Study 2016. Lancet Neurol. 2019 Jan;18(1):88-106. https://doi.org/10.1016/ S1474-4422(18)30403-4

4. Livingston G, Sommerlad A, Orgeta V, Costafreda SG, Huntley J, Ames D, et al. Dementia prevention, intervention, and care. Lancet. 2017 Aug;390(10113):2673-734. https://doi.org/10.1016/S01406736(17)31363-6
5. Oliveira D, Jun Otuyama L, Mabunda D, Mandlate F, GonçalvesPereira M, Xavier M, et al. Reducing the number of people with dementia through primary prevention in Mozambique, Brazil, and Portugal: an analysis of population-based data. J Alzheimers Dis. 2019 Aug;70(Suppl 1):S283-91. https://doi.org/10.3233/JAD-180636

6. Ferretti C, Sarti FM, Nitrini R, Ferreira FF, Brucki SMD. An assessment of direct and indirect costs of dementia in Brazil. PLoS One. 2018 Mar;13(3):e0193209. https://doi.org/10.1371/journal.pone.0193209

7. Ferri CP, Oliveira D. Harmonization of epidemiological studies on dementia in Latin America Why does it matter? Dement Neuropsychol. 2019 Oct-Dec;13(4):363-6. https://doi. org/10.1590/1980-57642018dn13-040001

8. Nitrini R, Caramelli P, Herrera E Jr, de Castro I, Bahia VS, Anghinah $\mathrm{R}$, et al. Mortality from dementia in a community-dwelling Brazilian population. Int J Geriatr Psychiatry. 2005 Mar;20(3):247-53. https:// doi.org/10.1002/gps.1274

9. Nitrini R, Barbosa MT, Dozzi Brucki SM, Yassuda MS, Caramelli P. Current trends and challenges on dementia management and research in Latin America.J Glob Health. 2020 Jun;10(1):010362. https://doi.org/10.7189/jogh.10.010362 